\title{
Strength mobilization of cement-treated marine clay with various curing time
}

\author{
Go.Kang ${ }^{\text {i) }}{ }^{\text {T. Tsuchida }}{ }^{\text {ii) }}$ H. Wakioka ${ }^{\text {iii) }}$ and Ys. Kim ${ }^{\text {iv }}$ \\ i) PhD Student, Department of Civil and Environmental Engineering, Hiroshima University, 1-4-1, Kagamiyama, Higashi-Hiroshima, \\ 730-8526, Japan. \\ ii) Professor, Department of Civil and Environmental Engineering, Hiroshima University. \\ iii) Master student, Department of Civil and Environmental Engineering, Hiroshima University. \\ iv) Professor, Department of Marine and Civil Engineering, Chonnam National University, 96-1, Yeosu, Jeollanamdo, 550-740, \\ Republic of Korea.
}

\begin{abstract}
Cement-treated Dredged clays have been used as a construction materials, backfilling of quay wall, artificial barrier layer of waste disposal site and submerged embankment. However, strength mobilization has not been fully understood from immediately after mixing to long-term curing time. Hence, unconfined compression test and vane shear test were carried under different stages of curing time, i.e., ranging from 0.5 hours to 90 days. On the basis of results, it was found that the strength at 1 hour of curing can be estimated by initial water content and specific volume ratio by normalized liquid limit. In addition, strength mobilization can be divided two stages depending on curing time; first stage within 3 days and second stage after 3 days. The formulas to estimate strength of cementtreated marine clay were proposed based on strength at 1 hour of curing and ratio of strength inclement before and after 3 days, and combined with previously proposed formula related to volumetric solid content.
\end{abstract}

Keywords: cement-treated clay, un-drained shear strength, unconfined compressive strength, initial water content, specific volume ratio

\section{INTRODUCTION}

A large amount of dredged clays have been dumped into waste-dumping sites enclosed by the seawalls annually to maintain the navigation channel or to accept the larger vessels in seaport. The lack of surplus of dumping capacity and the high cost for construction of closed waste-dumping site has been a serious problem (Tsuchida et al., 1996; Tang et al., 2001). For this reason, many researchers have developed the cementtreated clay, in which the chemically treated dredged clay is reused as a filling material in port and harbor projects (Tsuchida 1999; Watabe et al., 2011). For several decades, the study of cement-treated soil has been reported for many factors affecting strength mobilization by many researchers (Consoli et al., 2000; Larsson, 2001; Horpibulsuk et al., 2004). In addition, empirical formulas based on various indices have been proposed by several researchers to predict the strength of cement-treated soil to long-term curing (Kasama et al., 2006; Chiu et al., 2008; Sasanian et al., 2014). However, the strength mobilization of cement-treated clay from immediately after mixing to long-term curing after mixing has not studied well until now. Hence, the laboratory vane shear and unconfined compression tests were carried out on Tokuyama port clay with initial water contents and cement contents to verify the strength mobilization with various curing times ranging from 0.5 hours to 90 days. In this study, strength at 1 hour of curing was correlated with initial water content and volume ratio normalized by liquid limit. Two strength increment coefficients, which are gradients of the relationship between strength and curing time, according to stages before and after the 3 days could be 
obtained by associating cement content, respectively. Accordingly, formulas to estimate the strength of cement-treated clay were proposed on the basis of the strength at 1 hour of curing based on strength increment coefficients. The following formula was proposed by Tsuchida et al. (2012) as an empirical prediction of unconfined compressive strength with the theory of gelspace ratio in concrete engineering.

$$
q_{\mathrm{u}}=k_{\mathrm{c}}^{*}\left(c^{*}-c_{0}^{*}\right) Y^{\mathrm{N}}
$$

where, $k_{c}^{*}$ is a strength increasing factor, $\left(c^{*}-c_{0}^{*}\right)$ is an effect added cement rate, $Y$ is volumetric solid content, and $N$ is exponential parameter on void structure of cement-treated clay. $Y$ is defined as follows;

$$
Y=\frac{V_{\text {soils }}+V_{\text {cement }}}{V_{\text {soils }}+V_{\text {cement }}+V_{\text {void }}}
$$

where, $V_{\text {soils }}$ and $V_{\text {cement }}$ are volume of soil and cement, respectively. $V_{\text {void }}$ is volume of pore of cement-treated clay. Added cement rate $c^{*}$ is a ratio of mass of cement to total mass of solid particles, which include the cement particles and it is given in Eq. (3).

$$
c^{*}=\frac{m_{\mathrm{c}}}{m_{\mathrm{s}}+m_{\mathrm{c}}} \times 100(\%)
$$

where, $m_{s}$ and $m_{c}$ are dry mass of cement particles and clay particles, respectively. $c_{0}^{*}$ is a threshold of added cement rate, which means an initial cement volume to start hardening. The formula related to specific volume to estimate strength of cement-treated marine clay proposed in this study was combined with formula proposed by Tsuchida et al. (2012).

\section{METHODOLOGY}

Tokuyama port clay is used as material for experiments. The physical properties are presented in Table 1. Ordinary Portland cement $\left(\rho_{\mathrm{c}}: 3.15 \mathrm{~g} / \mathrm{cm}^{3}\right)$ is used as binder to prepare the specimen of cementtreated clay. Water content of cement-treated clay was arranged from 1.5 to 2 times liquid limit, $1.5 \mathrm{w}_{\mathrm{L}}$ and $2.0 \mathrm{w}_{\mathrm{L}}$, considering the variability of in-situ dredged clay. In order to observe the effect of strength increment due to addition of cement particle and also chemical reaction by cement, cement content defined in Eq.(3) was used. Mixing conditions and curing times are listed in Table. 2.

\section{Sample preparation}

The dredged clay was passed through $2 \mathrm{~mm}$ sieve to remove shell pieces and other coarse particles. The dredged clay and distilled water were cooled from $0^{\circ} \mathrm{C}$ to $2^{\circ} \mathrm{C}$ to prevent hardening due to hydration of cement during mixing. The cement milk was prepared by mixing cement and distilled water as $1: 1$ or 1:0.5 ratio. Subsequently, adding the cement milk into dredged clay, the slurry was thoroughly mixed for 30 minutes using vacuum mixer in the ice water at $0^{\circ} \mathrm{C}$. After mixing, the cement-treated clay was poured into the cylindrical mold $(60 \mathrm{~mm} \times 60 \mathrm{~mm})$ for vane shear test and summit mold $(50 \mathrm{~mm} \times 100 \mathrm{~mm})$ for unconfined compression test. After filling the mold with cement-treated clay, the cylindrical mold of vane shear test was cured under atmospheric pressure at a temperature of $20^{\circ} \mathrm{C} \pm 3^{\circ} \mathrm{C}$, the summit mold of unconfined compression test was cured under water at room temperature of $20^{\circ} \mathrm{C} \pm 3^{\circ} \mathrm{C}$. In this experiment, the starting time of curing was set to 30 minutes after mixing as time to prepare the specimen is required.

Table 1. Physical properties of Tokuyama port clay

\begin{tabular}{llll}
\hline Liquid & Plasticity & Ignition & Particle \\
limit & index & loss & density \\
$w_{L}(\%)$ & $I_{P}(\%)$ & $L_{i}(\%)$ & $\rho_{s}\left(\mathrm{~g} / \mathrm{cm}^{3}\right)$ \\
\hline 107.6 & 72.2 & 10.02 & 2.64 \\
\hline
\end{tabular}

Table 2. Mixing conditions and curing times

\begin{tabular}{lll}
\hline $\begin{array}{l}\text { Normalized } \\
\text { water content, }\end{array}$ & $\begin{array}{l}\text { Cement } \\
\text { content }\end{array}$ & Curing time \\
$\left(w / w_{L}\right)$ & $c^{*}(\%)$ & \\
\hline $1.5,2.0$ & $2,4,6,10$, & $0.5,2,5,7,10,15(\mathrm{hr})$ \\
& 15,20 & $1,2,3,7,28,90$ (days) \\
\hline
\end{tabular}

\subsection{Laboratory tests}

In this study, two laboratory experiments were conducted; unconfined compression test and vane shear test. At initial curing time, vane shear test was carried out for the samples as the specimen cannot stand by itself. Un-drained shear strength was calculated from Eq. (4).

$$
c_{\mathrm{u}}=\frac{M}{\pi\left(\frac{D^{3}}{6}+\frac{H D^{2}}{2}-\frac{d^{3}}{12}-\frac{d^{2} L a}{2}\right)}
$$

where, $M$ is the measured torque at peak $(\mathrm{kg} \cdot \mathrm{m}), D$ is the diameter of the vane, $H$ is the height of the vane, $d$ is diameter of the vane shaft $(2 \mathrm{~mm}), L$ is the contacted length of vane shaft, and $a$ is friction coefficient of shaft. Herein, $a$ is used as 1.0. The diameter and the height of the vane were $20 \mathrm{~mm}$ and $10 \mathrm{~mm}$, respectively. The shear rate of the laboratory vane apparatus was constant as $6^{\circ}$ to $12^{\circ}$ rotations per minute.

Unconfined compression test was carried out on the samples having strength to stand on its own. The unconfined compressive strength is the maximum vertical stress that a sample can sustain. The cementtreated samples were compressed at a strain rate of $1 \%$ per minute specified by Japanese Industrial Standards JISA 1216 (JISA1216, 2009).

\section{DATA ANALYSIS AND RESULT}

The strength of cement-treated clay is presented either $2 s_{\mathrm{u}}$ or $q_{\mathrm{u}}$. 


\subsection{Strength mobilization with curing time}

Fig. 1 shows the relationship strength mobilization with curing time, ranging from 0.5 hours to 90 days. From this relationship, it can be observed that strength considerably changes before and after the 3 days of curing. The strength mobilization can be divided into two stages; first stage (within 3 days) and second stage (after 3 days). In more than $10 \%$ of cement content, the strength within 3 days increases linearly with higher gradient than that of after 3 days in log-log scale. For the semi-log scale, the strength after 3 days is shown to be increased with logarithm curing time. It means that the ratio of strength increment is different depending on time before and after 3 days of curing. Therefore, the ratio of strength increment should be determined as two values by considering curing time of two stages. However, for less than $10 \%$ of cement content, the gradient of strength varies with the cement content.

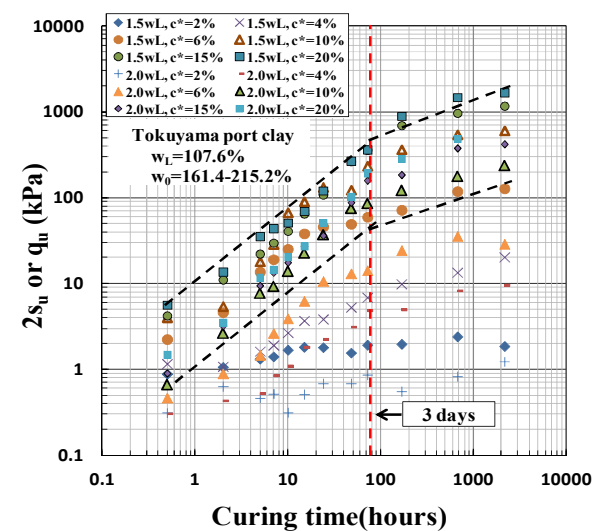

(a) Log-log scale

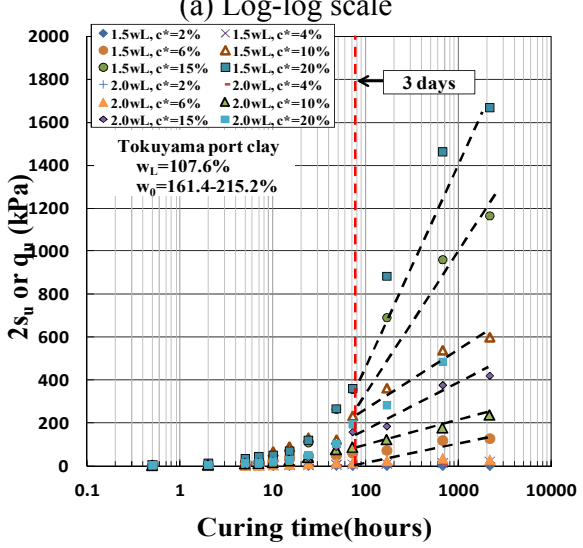

(b) Semi-loge scale

Fig. 1. Relationship between strength mobilizations with curing time

From Fig. 1(a), the strength mobilization with curing time within 3 days can be expressed as Eq. (5) and (5)'.

$$
\begin{gathered}
\ln \left(q_{\mathrm{u}} \text { or } 2 s_{\mathrm{u}}\right)=\ln \left(a_{1}\right)+b_{1} \ln (t) \\
q_{\mathrm{u}} \text { or } 2 s_{\mathrm{u}}=a_{1} t^{b_{1}}
\end{gathered}
$$

where, $t$ is curing time, $a_{1}$ is strength at 1 hour of curing and $b_{1}$ is the rate of strength increasing within 3 days (gradient of the graph drawn in $\log -\log$ scale). The $a_{1}$ at
1 hour of curing was correlated with indices, initial water content and specific volume ratio normalized by liquid limit. In this study, the initial water content and specific volume ratio were defined as shown in Eqs. (6) and (7).

$$
w^{\prime}=\frac{m_{\mathrm{w}}}{m_{\mathrm{s}}+m_{\mathrm{c}}}
$$

where, $m_{\mathrm{s}}$ and $m_{\mathrm{c}}$ are the mass of soil and cement, respectively, and $m_{\mathrm{w}}$ is the mass of water.

$$
v^{\prime}=\frac{v_{\mathrm{s}}+v_{\mathrm{c}}+v_{\mathrm{w}}}{v_{\mathrm{s}}+v_{\mathrm{c}}}
$$

where, $v_{\mathrm{s}}$ and $v_{\mathrm{c}}$ are volume of soil and cement, and $v_{\mathrm{w}}$ is volume of water. These equations are calculated considering cement and soil as solid. Fig. 2 shows the relationship between $a_{1}$ and normalized water content. Fig. 3 gives the relationship between $a_{1}$ and normalized specific volume ratio. Moreover, to compare the differences in the strength, the un-drained shear strength for untreated clays is drawn as in discontinuous line in Figs. 2 and 3. As shown Figs. 2 and 3, logarithm of $a_{1}$ can be expressed with logarithm of normalized water content and volume ratio as given in Eqs. (8) and (9).

$$
\begin{array}{r}
\ln \left(a_{1}\right)=c_{1}-c_{2} \ln \left(w^{\prime} / w_{L}\right) \\
a_{1}=\exp \left(c_{1}\right)\left(w^{\prime} / w_{L}\right)^{-c_{2}}
\end{array}
$$

where, parameter $c_{1}$ is logarithm of strength, i.e $\ln \left(a_{1}\right)$, when the initial water content is equal to liquid limit. Parameter, $c_{2}$ is a gradient of relationship between the strength and the normalized water content.

$$
\begin{array}{r}
\ln \left(a_{1}\right)=d_{1}-d_{2}\left(I_{v}-1\right) \\
a_{1}=\exp \left(d_{1}+d_{2}\right) v^{\prime-n}
\end{array}
$$

where, $n=d_{2} / \ln v_{L}, I_{v}=\ln v^{\prime} / \ln v_{L}$, parameter $d_{1}$ is logarithm of strength, i.e $\ln \left(a_{1}\right)$, when the specific volume ratio is equal to liquid limit. Parameter, $d_{2}$ is a gradient of relationship between the strength and the normalized specific volume ratio. In addition, to determine the value of $\ln \left(a_{1}\right)$ less than $10 \%$ of cement content in more detail, the experiment was additionally carried out with small cement content, $3 \%, 5 \%$, and $8 \%$. Form Figs. 2 and 3, it was found that the strength $a_{1}$ at 1 hour of curing can be classified into three trends by cement content; $c^{*}=2-5 \%, c^{*}=6-8 \%$, and $c^{*}=10-20 \%$ and values of each parameter according to cement content are listed in Table 3 . The values of parameters, $c_{2}$ and $d_{2}$, are close to gradient of untreated clay for the relationship strength $a_{1}$ at 1 hour of curing and normalized initial water content and normalized specific volume ratio and kept to constant value, 4.8 and 6.9 respectively, to easily compare the strength increment with untreated clay. The parameters, $c_{1}$ and $d_{1}$, are determined by regression analysis after keeping the gradient at constant value. 
Table 3. Parameters of $a_{l}$ according to cement content

\begin{tabular}{lllll}
\hline Cement content, $c^{*}(\%)$ & $c_{1}$ & $c_{2}$ & $d_{1}$ & $d_{2}$ \\
\hline $2-5$ & 1.77 & 4.8 & 1.38 & 6.9 \\
\hline $6-8$ & 2.78 & 4.8 & 2.39 & 6.9 \\
\hline $10-20$ & 3.08 & 4.8 & 2.75 & 6.9 \\
\hline
\end{tabular}

In Figs. 2 and 3, it was observed that the strength $a_{1}$ at 1 hour of curing is greater from 1.3 to 9.8 times than that of untreated clay. In addition, it can be seen that the strength $a_{1}$ at 1 hour of curing forms the three groups according to the cement content and the strength $a_{1}$ does not depend on initial water content except for $6 \%$ of cement content. Accordingly, cement content, ranging from $6 \%$ to $8 \%$, have threshold of strength mobilization, which is influenced by initial water content.

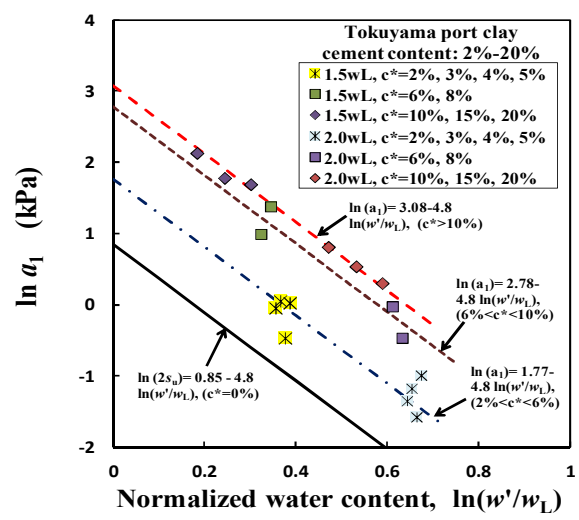

Fig. 2. Relationship between $\ln a_{1}$ and $\ln \left(w^{\prime} / w_{\mathrm{L}}\right)$

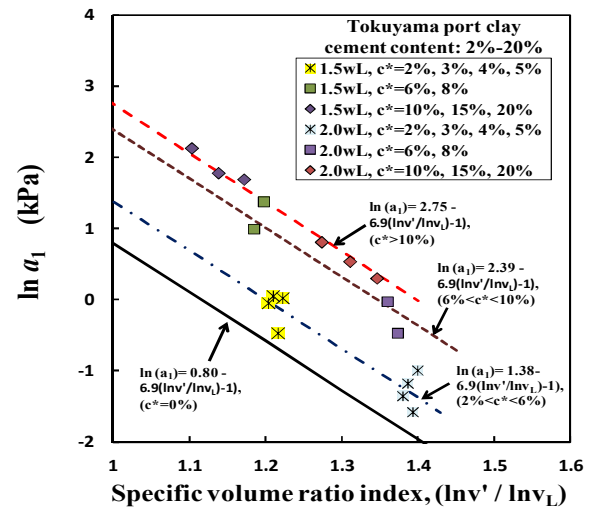

Fig. 3. Relationship between $\ln a_{I}$ and $\ln \left(\ln v^{\prime} / \ln v_{\mathrm{L}}\right)$

The strength increasing coefficient $b_{1}$ within 3 days was correlated with cement content. The $b_{1}$ was obtained from gradient of the logarithm of the curing time within 3 days and the logarithm of the strength in the log-log scale. Fig. 4 shows the strength increment coefficient $b_{1}$ with cement content. The $b_{1}$ is close to zero when cement content is very small, $2 \%$. From Fig. 4 , the strength increment coefficient before 3 days of curing is expressed as in Eq. (10).

$$
b_{1}=e_{1} \ln \left(c^{*}-e_{2}\right)+e_{3}
$$

where, $e_{1}$ and $e_{3}$ are strength increment parameters within 3 days of curing, and $e_{2}$ is threshold of cement content for strength gain of treated clay. In this study, $e_{1}$ and $e_{2}$ are 0.234 and 1.53 , respectively. $e_{3}$ is 0.34 . The parameters $e_{1}, e_{2}$, and $e_{3}$ are determined by $b_{1}-\left(c^{*}-e_{2}\right)$ relationship to keep the $e_{1}$ value as 0.234 . The $b_{1}-\left(c^{*}-e_{2}\right)$ relationship was assuming the value of $e_{2}$ when coefficient of determination $R^{2}$ was at its maximum.

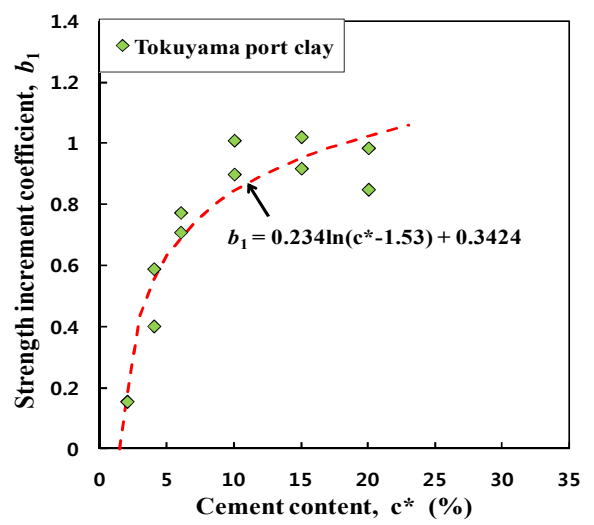

Fig. 4. Strength increasing coefficient $b_{1}$ within 3 days with cement content

The proposed Eqs. (8) and (9) can be used to calculate the strength $a_{1}$ at 1 hour of curing. Eq. (10) can determine the strength increment coefficient $b_{1}$. Eq. (11) to estimate the strength within 3 days of curing is obtained by substituting Eqs. (8) and (10) into Eq. (5).

$$
q_{\mathrm{u}}=\exp \left(c_{1}\right)\left(w^{\prime} / w_{\mathrm{L}}\right)^{-c_{2}} \cdot t^{e_{1} \ln \left(c^{*}-e_{2}\right)+e_{3}}
$$

Eq. (11) can be rearranged as shown in Eq. (12)

$$
q_{\mathrm{u}}=\exp \left(c_{1}\right)\left(w^{\prime} / w_{L}\right)^{-c_{2}} \cdot t^{e_{3}}\left(c^{*}-e_{2}\right)^{e_{1} \ln t}
$$

When $t$ is 72 hours, Eq. (13) can be expressed

$$
q_{\mathrm{u}}=\exp \left(c_{1}\right) \cdot 72^{e_{3}}\left(c^{*}-e_{2}\right)^{e_{1} \ln t}\left(w^{\prime} / w_{\mathrm{L}}\right)^{-c_{2}}
$$

Subsequently, Eq. (14) can be obtained substituting Eqs. (9) and (10) into Eq. (5).

$$
q_{\mathrm{u}}=\exp \left(d_{1}+d_{2}\right) v^{\prime}-n \cdot t^{e_{1} \ln \left(c^{*}-e_{2}\right)+e_{3}}
$$

Eq. (14) can be transformed as shown in Eq. (15).

$$
q_{\mathrm{u}}=\exp \left(d_{1}+d_{2}\right)\left(1 / v^{\prime}\right)^{n} \cdot t^{e_{3}}\left(c^{*}-e_{2}\right)^{e_{1} \ln t}
$$

When $t$ is 72 hours, Eq. (15) becomes Eq. (16).

$$
q_{\mathrm{u}(72)}=\exp \left(d_{1}+d_{2}\right) \cdot 72^{e_{3}}\left(c^{*}-e_{2}\right)\left(1 / v^{\prime}\right)^{n}
$$

where, $N=n=d_{2} / \ln v_{\mathrm{L}}$

Eq. (16) is the same form with Eq. (1) proposed by Tsuchida et al. (2012) as shown Eq. (17). Here, $e_{1}$ was fixed at 0.234 to make the linear equation.

$$
\begin{gathered}
q_{\mathrm{u}}=k_{c}^{*}\left(c^{*}-c_{0}^{*}\right) Y^{N} \\
q_{\mathrm{u}(72)}=\left[\exp \left(d_{1}+d_{2}\right) \cdot 72^{e_{3}}\right]\left(c^{*}-e_{2}\right) Y^{N}
\end{gathered}
$$


The strength increment factor $k_{c}^{*}$ can be calculated by $\exp \left(d_{1}+d_{2}\right) \cdot 72^{e_{3}} . c_{0}^{*}$ is similar to parameter $e_{2}$. The volumetric solid content $Y$ is equivalent to the inverse of specific volume $1 / v$. N is related to parameter $d_{2}$ and specific volume of liquid limit of dredged clay.

\subsection{Strength mobilization characteristics after 3 days of curing}

As mentioned above, the rate of strength increment coefficient changes according to curing time before and after 3 days. In this part, formula to estimate the strength after 3 days of curing is proposed as in Eq. (18).

$$
q_{\mathrm{u}}=q_{\mathrm{u}(72)}\left[1+b_{2} \ln (t / 72)\right]
$$

where, $q_{\mathrm{u}(72)}$ is the strength when curing time is 3 days. $b_{2}$ is strength increment coefficient after 3 days of curing (gradient of relationship between strength and logarithm curing time). As shown Fig. 1(b), the strength mobilization after 3 days of curing is linearly increased with logarithm curing time. The $b_{2}$ can be determined from gradient after 3 days of curing in Fig. 1(b). Fig. 5 demonstrates the relationship between $b_{2}$ and cement content. The $b_{2}$ is linearly increased with the cement content. The $b_{2}$ is determined by regression analysis conducted based on all data and expressed in Eq. (19).

$$
b_{2}=f_{1} \cdot c^{*}+f_{2}
$$

where, $f_{1}$ and $f_{2}$ are strength increment parameters after 3 days of curing. In this study, $f_{1}$ and $f_{2}$ are 0.05 and 0.07 , respectively.

When Eq. (19) is substituted into Eq. (18), the strength can be estimated by Eq. (20) as follows.

$$
q_{\mathrm{u}}=q_{\mathrm{u}(72)}\left[1+\left(f_{1} \cdot c^{*}+f_{2}\right) \ln (t / 72)\right]
$$

\subsection{Application of formula to estimate the strength of cement-treated clay}

Figs. 6 and 7 are the comparison of measured strengths, $2 s_{\mathrm{u}}$ and $q_{\mathrm{u}}$, and strengths calculated by formulas proposed in this study. These figures show good agreements between measured strengths and calculated strengths for most of the data. However, there were some data to reach considerable variations up to 2 times than the measured value. The mean absolute percent errors are $29.35 \%$ and $25.65 \%$, respectively, when determining the strength based on index of initial water content and index of specific volume ratio. It was found that the calculated strengths based on index of specific volume ratio are more accurate than strengths calculated by index of initial water content. It means that the strength $a_{1}$ at 1 hour of curing obtained based on index of specific volume ratio is better than that obtained based on index of water content.

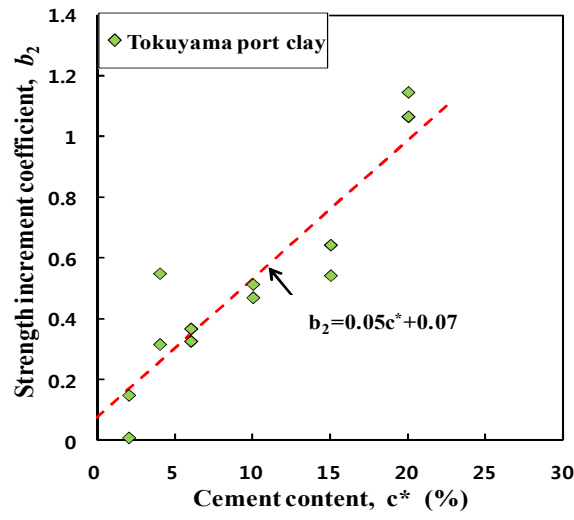

Fig. 5. Strength increasing coefficient $b_{2}$ after 3 days with cement content

\subsection{Application of formula to estimate the strength of cement-treated clay}

Figs. 6 and 7 are the comparison of measured strengths, $2 s_{\mathrm{u}}$ and $q_{\mathrm{u}}$, and strengths calculated by formulas proposed in this study. These figures show good agreements between measured strengths and calculated strengths for most of the data. However, there were some data to reach considerable variations up to 2 times than the measured value. The mean absolute percent errors are $29.35 \%$ and $25.65 \%$, respectively, when determining the strength based on index of initial water content and index of specific volume ratio. It was found that the calculated strengths based on index of specific volume ratio are more accurate than strengths calculated by index of initial water content. It means that the strength $a_{1}$ at 1 hour of curing obtained based on index of specific volume ratio is better than that obtained based on index of water content.

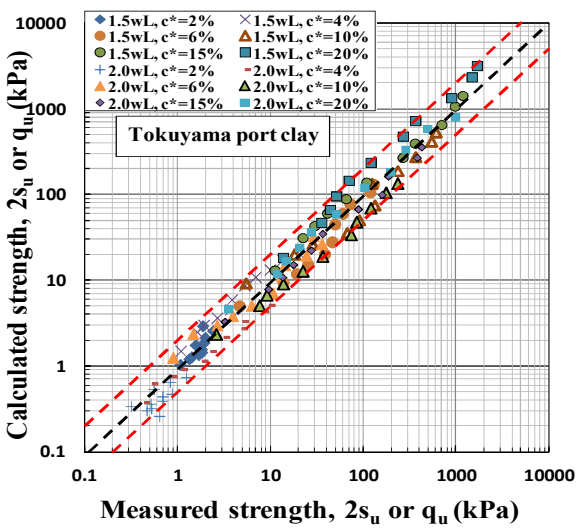

Fig. 6. Comparison of measured strength and strength calculated by index of normalized initial water content 


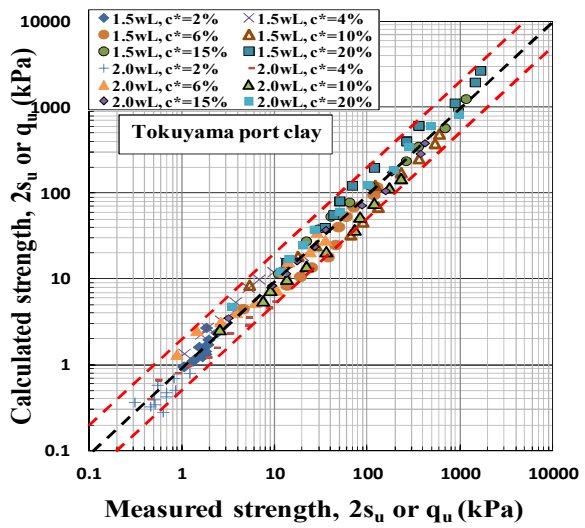

Fig. 7. Comparison of measured strength and strength calculated by index of normalized initial water content

\section{CONCLUSIONS}

Following conclusions can be drawn.

(1) The strength mobilization of cement-treated clay changes before and after 3 days of curing, and can be divided into two stages; first stage (within 3 days) and second stage (after 3 days).

(2) The strength $a_{1}$ at 1 hour of curing can be determined by water content or specific volume normalized by liquid limit for cement-treated clay, which cement is considered as solid particle. The three linear relationships are obtained for the ranges of cement content, $2-5 \%, 6-8 \%$ and $10-20 \%$, respectively in $\ln \left(a_{1}\right)-\ln \left(w^{\prime} / w_{\mathrm{L}}\right)$ and $\ln \left(a_{1}\right)-\ln \left(v^{\prime} / v_{\mathrm{L}}\right)$.

(3) The strength increment coefficient $b_{1}$ within 3 days (first stage) was nonlinearly increased with curing time, while the strength increment coefficient $b_{2}$ after 3 days (second stage) was linearly increased with curing time as following equation.

(4) The formulas within 3 days of curing were proposed based on strength at 1 hour and strength increment coefficient $b_{1}$. For curing time of 72 hours, the formula based on specific volume ratio is same form as that related to volumetric content proposed by Tsuchida et al., (2012).

(5) The strength of cement-treated clay after 3 days was proposed by combining the strength of 72 hours of curing and strength increment coefficient $b_{2}$ after 3 days of curing. The strengths calculated by the proposed formulas agreed fairly well with measured strengths.

\section{REFERENCES}

1) Consoli, N.C., Rotta, G.V. and Prietto, P.D.M. (2000):
Influence of curing under stress on the triaxial response of cemented soils, Geotechnique, 50(1), 99-105.

2) Chiu, C.F., Zhu, W. and Zhang, C.L. (2008): Yielding and shear behavior of cement-treated dredge materials, Engineering Geology, 103(1), 1-12.

3) Horpibulsuk, S., Miura, N. and Bergado, D.T. (2004): Undrained shear behavior of cement admixed clay at high water content, Journal of Geotechnical and Geoenvironmental Engineering, ASCE, 130(10), 10961105 .

4) Kasama, K., Zen, K. and Iwataki, K. (2006): Undrained shear strength of cement-treated soils, Solis and Foundations, 46(2), 221-232.

5) Larsson, S. (2001): Binder distribution in lime-cement columns, Ground Improvement, 5(3), 111-122.

6) Sasanian, S. and Newson, T.A. (2014): Basic parameters governing the behavior of cement-treated clays, Solis and Foundations, 54(2), 209-224.

7) Tang, Y. X., Miyazaki, Y. and Tsuchida, T. (2001): Practices of reused dredging by cement treatment, Soils and Foundations, 41(5), 129-143.

8) Tsuchida, T., Takeuchi, D., Okamura, T. and Kishida, T. (1996): Development of lightweight fill from dredgings, Environmental Geotechnics, Proceedings of the Second International Congress on Environmental Geotechnics, Balkema, pp. 415-420.

9) Tsuchida, T. (1999): Development and use of foamed treated soil in port and airport project, Report of Port and Harbour Research Institute, 38(2), 131-167 (in Japanese).

10) Tsuchida, T. and Tang, T.X. (2012): A consideration on estimation of strength of cement-treated marine clays, JGS, 7(3), 435-447 (in Japanese).

11) Watabe,Y. and Noguchi, T. (2011): Site-investigation and geotechnical design of D-runway construction in Tokyo Haneda Airport, Soils and Foundations, Vol.51, No6, 1003-1018. 